\title{
El Movimiento Estudiantil español durante el Franquismo (1965-1975)
}

The Spanish student movement under the Franco regime (1965-1975)

Le mouvement étudiant espagnol pendant le Franquisme (1965-1975)

\section{Miguel Gómez Oliver}

\section{(Q) OpenEdition}

\section{Journals}

Edición electrónica

URL: http://journals.openedition.org/rccs/652

DOI: $10.4000 /$ rccs. 652

ISSN: 2182-7435

Editor

Centro de Estudos Sociais da Universidade de Coimbra

Edición impresa

Fecha de publicación: 1 junio 2008

Paginación: 93-110

ISSN: 0254-1106

Referencia electrónica

Miguel Gómez Oliver, «El Movimiento Estudiantil español durante el Franquismo (1965-1975) »,

Revista Crítica de Ciências Sociais [En línea], 81 | 2008, Puesto en línea el 01 octubre 2012, consultado el 30 abril 2019. URL : http://journals.openedition.org/rccs/652 ; DOI : 10.4000/rccs.652 


\section{MIGUEL GÓMEZ OLIVER}

\section{El Movimiento Estudiantil español durante el Franquismo (1965-1975)}

Procede-se neste artigo a uma caracterização do movimento estudantil universitário espanhol durante as décadas de 1960 e 1970, observando-o enquanto instrumento fundamental na criação de espaços de liberdade na Espanha franquista, analisando o seu desenvolvimento orgânico, a sua capacidade para alimentar o desenvolvimento de uma cultura de debate, e examinando o papel que desempenhou na aprendizagem de práticas democráticas que depois foram transplantadas para outros ambientes sociais e políticos, tanto durante a fase final de afirmação da oposição antifranquista como mais tarde, durante a fase de transição para a democracia.

\section{Introducción}

El objetivo fundamental de estas páginas es caracterizar el Movimiento Estudiantil Universitario durante las décadas de 1960 y 1970, como un instrumento importante de creación de espacios de libertad en la España de la dictadura franquista; analizar, en segundo lugar, su evolución hacia diversas estructuras organizativas, la más importante de las cuales fueron los Sindicatos Democráticos de Estudiantes Universitarios (SDEU); en tercer lugar, examinar el papel que jugó este movimiento para el aprendizaje de prácticas democráticas en su seno que fueron capaces de transplantarse a otros ámbitos sociales y políticos, tanto entre la oposición antifranquista como después, durante la Transición a la democracia. Finalmente, también poner de relieve cómo el Movimiento Estudiantil fue capaz de crear una cierta cultura del debate para contribuir a construir una universidad democrática y, en esa medida, ayudar a la construcción de una ciudadanía democrática de carácter más generalizada. Naturalmente, el Movimiento Estudiantil Español no pudo actuar como sus homólogos de los países democráticos europeos. Hace dos meses, Sami Nair, a propósito de la revuelta estudiantil francesa contra la Ley de Primer Empleo (en nada parecida a la Revolución del 68, como todos los analistas se han apresurado a reconocer) señalaba que nunca un gobierno francés había conseguido triunfar frente a la contestación estudiantil, frecuentemente apoyada por otros sectores de una ciudadanía democrática. 
Nada que ver tampoco con las revueltas estudiantiles de los campus de Berkeley o de Berlín en 1968. El Movimiento Estudiantil Español, enfrentado a la dictadura, sufrió una feroz represión. Sólo algunos objetivos de índole académica fueron coronados por el éxito, aún a costa de duros enfrentamientos y castigos ejemplarizantes por parte de las autoridades académicas que no tuvieron empacho en delatar, expedientar, y expulsar de las aulas universitarias a los más caracterizados dirigentes estudiantiles.

Pese a todo, como trataré de demostrar, consiguió el apoyo de amplios sectores estudiantiles para sus reivindicaciones en pro de una universidad democrática, en un país igualmente democrático. Estoy convencido de que en ello residió su éxito, y también sus límites. No menos evidente resulta el hecho de que, en las filas del Movimiento Estudiantil, se formaron y curtieron buena parte de los dirigentes políticos, sindicales, sociales e intelectuales españoles durante la Transición política y durante los primeros veinte años de la democracia española.

\section{Los rasgos dominantes de la universidad franquista y las primeras luchas estudiantiles}

Durante la dictadura, la universidad - como todo el Régimen - enraíza su legitimidad en los planos ideológico, funcional y docente, en la victoria de la guerra civil en 1939 y sus ideales. De ahí que, desde el principio, tratase y consiguiese hacer borrón y cuenta nueva de la experiencia e influencia universitaria del periodo republicano a la que consideraban, en palabras de Alfonso Iniesta, alto cargo del Ministerio de Educación Nacional, miembro de la Acción Católica Nacional de Propagandistas (ACNP) y presidente que fue de la Confederación de Maestros Católicos, como "el foco de toda propaganda disolvente que convirtió el noble ejercicio docente en materia subversiva sin que el Gobierno tomara medidas enérgicas, ni la sociedad reaccionara con violencia" (apud Claret Miranda, 2005: 37).

Su bestia negra fue la Institución Libre de Enseñanza, a la que condenaban a desaparecer hasta de los libros de Historia, acusada de introducir en las aulas españolas ideas extranjeras, en detrimento de las esencias patrias para "acabar llevando al país a la decadencia". Frente a lo que cabría esperar, la universidad franquista no fue un feudo de Falange. Desde 1938, el Ministro de Educación, Pedro Sainz Rodríguez puso las bases del nacionalcatolicismo universitario, haciendo que todos los altos cargos recayesen sobre hombres de Acción Española y de la ACNP, con el objetivo de "recatolizar la universidad". 
El desmoche de la universidad republicana fue feroz y, aunque no hay excesivo acuerdo en los cálculos numéricos, de los 505 catedráticos en activo en 1935, 111 habían sido asesinados, exiliados o cesados según el Director General de Enseñanza Secundaria y Universitaria, José Pemartín, en 1939, aportando cifras muy maquilladas, que ampliará en 1946, declarando que 97 catedráticos están separados de la docencia por depuración; 100 habían muerto (eso sí, sin discriminar entre fusilados y fallecidos de muerte natural); y 93 se habían jubilado, al tiempo que 21 habían retornado al servicio activo tras cumplir la "sanción impuesta": 290 sobre 503, que era el número total de la plantilla de catedráticos de universidad en 1936.

Independientemente de la magnitud de las cifras, lo más escandaloso es que tal desmoche es asumido por el Régimen, porque se trataba de un "penoso deber que cumplimos con espíritu de servicio para contribuir a que no se pierda el esfuerzo enorme de la guerra", decía un Boletín Ministerial de octubre de 1939, aunque el Ministro del Ramo, en sus papeles personales, calificó el éxodo intelectual "como uno de los más graves problemas que la guerra civil plantea a la cultura española”, reconociendo que sólo se podía comparar tal sangría con "la emigración de los afrancesados" a principio del siglo XIX (Claret Miranda, 2005: 369).

Considero importante traer a colación esta situación de depuración de la universidad española de postguerra porque la otra cara de la moneda es que tras las expulsiones, alguien se benefició. Y la progresiva y casi inmediata cobertura de las cátedras universitarias por fieles y adictos al régimen supuso una suerte de recompensa a quienes se habían comprometido desde temprana hora con los golpistas, convirtiéndose así la universidad en un instrumento creador de consenso dentro de las filas de los vencedores, independientemente de las familias políticas de que procediesen.

Pero también, porque al efecto concreto de estas páginas es preciso tener en cuenta que quienes accedieron de este modo a las cátedras de la universidad española de los años 40 , en su inmensa mayoría continuaban en activo durante los años 60 e incluso 70; configuraban el sector dominante de la universidad española cuando se desarrolla el Movimiento Estudiantil, al que en buena parte de los casos se oponen con todas sus fuerzas; en otros, no entienden absolutamente nada de lo que acontece y solo una exigua minoría (parte de la cual es separada de sus cátedras en los años 60) lo apoya más o menos abiertamente.

Una universidad, escribía Nicos Poulantzas, en 1975, atravesada por fuertes contradicciones debidas "al ascenso prodigioso de las luchas estu- 
diantiles" que, en casos excepcionales, llegaron a implicar a ciertos agentes de la cúpula universitaria. Por su parte, el Régimen no hizo más que reforzar la dictadura corporatista e intelectual que ejercían los catedráticos (Poulantzas, 1976: 106). Apuntando que, incluso algunos establecimientos de enseñanza superior dependientes de la Iglesia Católica (sobre todo de los jesuitas,) eran mas liberales que los del Estado.

En este clima enrarecido y mediocre de la universidad española, fuertemente controlada por la dictadura, surge, sin embargo, una primera protesta estudiantil en febrero de 1956, muy circunscrita a la Universidad de Madrid, que dirige su oposición contra el SEU (Sindicato Español Universitario, única fórmula de representación de estudiantes y profesores en la universidad española franquista) y la falta de libertad a la hora de elegir representantes estudiantiles. Al mismo tiempo, intentan convocar un Congreso Libre de Estudiantes para exigir la reforma y democratización de la universidad.

Para el Régimen, esta primera rebelión estudiantil constituye toda una sorpresa. Sus protagonistas son hijos de los vencedores, que configuran una nueva generación, la primera que accede a las aulas universitarias sin haber vivido directamente el trauma de la Guerra Civil y que ya no considera al franquismo como el régimen salvador de la patria, sino como una pesada rémora que obstaculiza, incluso, su propia formación académica y que actúa contra ellos mediante la represión.

Obviamente, antes de esta primera protesta, la universidad era un lugar, un espacio, de encuadramiento político e ideológico del franquismo. No sólo de los profesores, que habían ocupado sus cátedras más por adhesiones políticas que por valía intelectual. También de los estudiantes. El consenso en la universidad se había establecido bajo el compromiso de unos estudiantes cuyos títulos les permitirían acceder a las élites de la Administración del Estado y, sobre todo, sobre el silencio, la mediocridad cultural y el ventajismo intelectual.

Ciertamente, los partidos políticos ilegales y clandestinos (especialmente, el Partido Comunista de España - PCE -, que ha enviado a Madrid a Jorge Semprún para organizar a los intelectuales y a los estudiantes universitarios) están actuando en la universidad madrileña. Los graves enfrentamientos entre estudiantes se saldan, como es sabido, con la muerte de un joven falangista y la detención de buena parte de los organizadores de la protesta. Las consecuencias políticas no se hacen esperar: Franco cesa al Rector de la Universidad de Madrid, Pedro Laín Entralgo, y al Ministro de Educación, el católico Joaquín Ruiz Jiménez, al considerarlos excesivamente liberales. 
Este primer choque con la estructura oficial de la universidad, pese a su carácter incipiente, daría un fuerte impulso al Movimiento Estudiantil en los años siguientes. La lucha se lleva a cabo en diversos frentes. Por un lado, comienza la penetración de estudiantes demócratas en las filas del SEU, que permitirá multiplicar actividades culturales, crear boletines y revistas que escapan a la censura, en cierto modo; publicar encuestas e informes críticos sobre la marcha de las clases en las aulas universitarias que se elevan a las autoridades académicas; se inician contactos con obreros y campesinos a través del "Servicio Universitario del Trabajo" (sector especializado del SEU), etcétera que, sin ninguna duda a mi juicio, constituyeron formas diversas de concienciación, de construcción y de práctica de ciudadanía democrática.

Por otro lado, en el curso 1960-1961 se consigue un nuevo triunfo: elegir libremente a los delegados de curso y de centro que el propio gobierno reconocerá mediante un Decreto de septiembre de 1961. Este triunfo permitirá que, por fin, comiencen a aparecer consignas claramente políticas dentro del movimiento estudiantil, como la lucha por la amnistía para los estudiantes represaliados, o la solidaridad con los mineros asturianos en 1962.

En diversas universidades españolas, principalmente las de Madrid y Barcelona, habían aparecido grupos clandestinos, como FUDE (Federación Universitaria Democrática Española) que coordina la penetración de los estudiantes demócratas en el SEU y la lucha en su interior para ir desplazando paulatinamente a los jerarcas estudiantiles impuestos por el gobierno y que intentan debilitar la influencia de su burocracia, hasta el punto de que, hasta el curso 1963-1964, en las universidades de Barcelona y Sevilla los representantes elegidos por los estudiantes proclamaron la ruptura con las jerarquías no electas del SEU. Al año siguiente, la rebelión se extiende a Madrid y a otras universidades reclamando, por primera vez, un nuevo sindicato democrático e independiente de estudiantes, capaz de impulsar el principal objetivo del movimiento estudiantil en esos años: la reforma y la autonomía universitaria. ${ }^{1}$

En resumen, esta dialéctica entre estructuras obsoletas y jerarquías del Régimen en el SEU y en las cúpulas universitarias y los inicios de un Movimiento Estudiantil, compuesto por jóvenes generaciones que ya estaban viviendo el comienzo del despegue económico del país, que comenzaban a contactar con el movimiento obrero y que estaban muy influidos por los partidos políticos de la oposición, van creando y extendiendo poco a

\footnotetext{
${ }^{1}$ En adelante, vamos a seguir la recopilación de textos publicados por Fernández Buey, 1977.
} 
poco la impresión - y la convicción - de que la situación de la universidad podía y debía cambiar.

Que era posible alcanzar la democracia y la reforma de la institución y, con ella, la del país. Porque, probablemente, una de las características fundamentales del movimiento universitario español de los primeros años sesenta fue - como lo seguiría siendo posteriormente - la idea de unir la lucha por la democracia en la universidad, con la lucha por la democracia en España.

\section{La universidad se rebela. $1964-1968$}

Durante los años 60, la punta de lanza del movimiento estudiantil fue la Universidad de Barcelona, y no por azar. Cataluña es una de las zonas más ricas e industrializadas de la España de la época, con una potente burguesía ilustrada que ha mantenido, en buena parte, grandes distancias con el Régimen; con una fuerte carga ideológica cultural catalanista y nacionalista apoyada, en muchas ocasiones, por la Iglesia (no olvidemos, por ejemplo, el papel de guardián y animador de la cultura catalana que juega el Monasterio de Montserrat y su abad, Mossen Escarré); con una fuerte implantación en el movimiento obrero y en la universidad del Partido Socialista Unificado de Cataluña (PSUC, la rama del PCE en Cataluña, constituida como partido independiente), capaz de unir en su seno comunismo y catalanismo; Cataluña era la región más cercana a Europa y a sus influencias, y no sólo por cuestiones geográficas, sino por un acusado cosmopolitismo económico y cultural. No es, pues, de extrañar que sea en esa universidad donde, de forma mas clara, los estudiantes analicen y diagnostiquen la situación de la universidad española y lancen propuestas alternativas de carácter organizativo, académico y sociopolítico.

Así, en marzo de 1964, la Cámara de Estudiantes de Ciencias Económicas de Barcelona da a conocer en su revista oral "Siega" un análisis de la situación (Fernández Buey, 1977: 9-18). Considera los problemas de la universidad como consecuencia y reflejo de los problemas generales de la sociedad: un régimen político dictatorial, con una doctrina oficial cuyas normas prohibitivas y defensivas impiden la libertad de pensamiento. Rasgos todos ellos que tienen una influencia deformante sobre la universidad, a la que se considera un centro elitista, reservado a las clases altas y medias, pero seleccionado desde el punto de vista académico; con un profesorado seleccionado de forma dudosa y poco garantista, que permite la existencia de muchos catedráticos incompetentes; con unos planes de estudio mal elaborados, en cuya concepción y ejecución los estudiantes no tienen ni voz ni voto, y a quienes tampoco se reconoce su 
experiencia en temas fundamentales, como los referidos a métodos de enseñanza, sistemas de evaluación, relaciones entre profesores y alumnos, etcétera. Una universidad muy mal dotada económicamente y peor administrada. De ahí, continúan, que los estudiantes no conciban su trabajo como una responsabilidad intelectual, que no estén orientados en sus estudios, y que la universidad se encuentre aislada de los problemas del país.

Tras este diagnóstico, demoledor, los resultados son - según los estudiantes - igualmente demoledores: un bajísimo nivel intelectual; la esterilidad de la enseñanza impartida desde las cátedras, y el desarrollo de la trampa y de la hipocresía como única arma de defensa por parte de los alumnos. Como propuesta capaz de resolver la situación - y, desde luego, con buena dosis de ingenuidad - la necesidad de unos medios de expresión para los estudiantes, concretados en la creación de un Sindicato, que haga tomar conciencia a los alumnos de sus derechos y deberes y que garantice su ejercicio. Un sindicato independiente y representativo, diferenciado de las autoridades políticas y académicas y con capacidad de diálogo frente a ellas, condiciones todas que, pese al entrismo, el SEU no cumple.

Considero que, en fechas tan tempranas como 1964, que se lleve a cabo un diagnóstico de la situación universitaria tan clara y radical, dice mucho de la capacidad de análisis y percepción de la realidad que tienen los estudiantes, a pesar de considerar al sindicato como una suerte de varita mágica capaz, por si sola, de solucionar los problemas y reformar la institución. Probablemente, el recurso a "recetas organizativas" sea uno de los mayores handicaps del Movimiento Estudiantil Español. Pero no es menos cierto que cuando logran imponerlo, la universidad española se convierte en uno de los escasos espacios de libertad en la España de la dictadura, y también en un laboratorio en el que se aprende y se practica, con todos los errores e insuficiencias que queramos, hábitos democráticos tan fundamentales como la libre discusión, el debate, la negociación con autoridades académicas, la libertad de expresión y asociación (pese a los riesgos), así como el empeño en la mejora académica (docente e investigadora) de la institución.

Quizá una de las pruebas que mejor demuestran el éxito de las propuestas estudiantiles sea la carta dirigida por 1.161 intelectuales españoles al Ministro de Información y Turismo, Manuel Fraga Iribarne en marzo de 1965, solidarizándose con los obreros y los estudiantes represaliados y reclamando libertad de asociación y de sindicación, libertad de expresión e información, derecho a la huelga y libertad para los represaliados, 
así como rehabilitación de los estudiantes expedientados como resultado de las luchas estudiantiles.

$\mathrm{Y}$ es que debemos recordar que, a las propuestas del Movimiento Estudiantil, la dictadura respondió de la única forma que sabía hacerlo: mediante la represión policial y judicial, que llevó a prisión a cientos de dirigentes estudiantiles, o a través de la represión académica con expedientes, pérdida de matrículas y becas, e, incluso, expulsión de la universidad. Medidas, que no sólo se llevan a cabo en la primera mitad de la década de los 60, sino que perdurarían hasta la muerte de Franco; incluso, de forma tan sofisticada como la creación del Tribunal de Orden Público (TOP), destinado a juzgar delitos políticos, o las declaraciones de estados de excepción (apelando al Fuero de los Españoles) en todo o en parte del territorio nacional que, en más de una ocasión, tuvieron en su punto de mira al Movimiento Estudiantil.

$\mathrm{Y}$ aunque como es sabido el inspirador de la carta antes citada fue el PCE que, en su VI Congreso, había aprobado la célebre "Alianza de las Fuerzas del Trabajo y de la Cultura" como táctica para conseguir la acumulación de fuerzas necesaria para derrocar al régimen e instaurar la democracia, no es creíble que, en 1965, los 1.161 firmantes fuesen afiliados comunistas, máxime cuando entre ellos encontramos señeras figuras democristianas, nacionalistas, e, incluso, antiguos falangistas.

Ese mismo mes, la Junta de Delegados Estudiantiles de la Universidad de Barcelona celebra una "Asamblea Libre de Distrito", el máximo órgano de una práctica democrática de carácter asambleario, ${ }^{2}$ cuyas conclusiones exigen el fin de la represión policial y académica, la abolición de la Ley de Universidades, vigente desde 1943, la supresión del SEU, que ya ha sido derrotado en todos los frentes de la representatividad estudiantil, la elaboración de una nueva Ley de Universidades en la que participen profesorado y alumnado bajo el respeto a la Autonomía de la Universidad, la racionalización de los recursos financieros, con un aumento sustancial de los mismos, y una política de enseñanza que reforme y ponga al día unos planes de estudios obsoletos que son considerados incapaces de asumir los nuevos retos del conocimiento científico y técnico; que aumente el número y calidad del profesorado, acabe con las cátedras vitalicias y reconozca la libertad de cátedra. Finalmente, y en otro orden de cosas, exigen la creación de un Sindicato Democrático de Estudiantes,

\footnotetext{
${ }^{2}$ Fernández Buey, 1977: 13-26. Esa declaración sería suscrita por la Primera Coordinadora Nacional de Estudiantes, reunida en Barcelona, con asistencia de 14 representantes de las universidades de Barcelona, Bilbao, Madrid, Salamanca, Valencia, Oviedo, Valladolid, y Zaragoza.
} 
que ahora se perfila con mayor nitidez y explícitamente se define como homólogo a las organizaciones estudiantiles europeas, en cuyos organismos internacionales quieren incluirse.

En el plano político español, perfilan aún más su propuesta porque en ello les iba la propia supervivencia: exigen la elegibilidad de todos sus miembros, en cada uno de los niveles de organización que les permitía una legitimidad de la que históricamente había carecido el SEU; establecían una cláusula de revocación de cargos como garantía democrática; no se obligaba a los estudiantes a la afiliación y, mucho menos, al activismo aunque exigían la participación estudiantil en los organismos rectores y consultivos del gobierno universitario, a través de sus representantes, y requerían los medios necesarios para expresarse con entera libertad, al tiempo que exigían el reconocimiento del derecho de huelga "una vez agotados todos los medios normales de defensa de los derechos de sus miembros" (Fernández Buey, 1977: 30).

La respuesta gubernamental a las exigencias estudiantiles fue de una impresionante estulticia, a mi juicio. No sabían, o probablemente, no querían enterarse de nada. Los estudiantes conocían que la pérdida del control de la universidad a través del SEU era grave para un gobierno que acababa de celebrar los "25 años de paz" y preparaba el referéndum sobre la Ley Orgánica del Estado como un inmenso plebiscito a la figura del Dictador que había conseguido la Paz, la estabilidad y el desarrollo económico, enfrentándose exitosamente a las insidias de la conspiración “judeo-comunista-masónica” en el interior del país, como proclamaba la propaganda del régimen. Conspiración, una de cuyas puntas de lanza era, precisamente, la contestación universitaria. Del mismo modo, el Régimen se enfrentaba, cuando menos, a la incomprensión de una Europa a la que pretendía incorporarse, aunque viciada por la ideología y comportamientos demoliberales que no podían compartir el proyecto de "democracia orgánica" diseñado por el régimen, ahora con la preciosa ayuda del Opus Dei, versión tecnocrática del nacionalcatolicismo imperante en los años 50.

También desde esta perspectiva, presuntamente reformista, el movimiento estudiantil y sus prácticas democrático-asamblearias cuestionó de forma decisiva la penúltima maniobra de adaptación y aceptación de la dictadura de una Europa occidental, también cautiva de las reglas del juego impuestas por la Guerra Fría.

La respuesta gubernamental a las exigencias y a la realidad de las más importantes universidades españolas (porque justo es decir que las doce universidades existentes respondieron con ritmos y comportamientos diferentes a las exigencias estudiantiles siendo, como hemos dicho, Bar- 
celona y Madrid las que con mayor fuerza mantuvieron las reivindicaciones.) La respuesta gubernamental, decimos, no se hace esperar, y supuso un primer triunfo para el Movimiento Estudiantil.

Mediante el Decreto de 7 de abril de 1965 intentan neutralizar los avances estudiantiles, sin empacho en enterrar las viejas estructuras del SEU $\mathrm{y}$, en una maniobra perfectamente lampedusiana, sustituirlo por otra estructura progubernamental que intentaba reabsorber las reivindicaciones estudiantiles y hacer fracasar la constitución de un Sindicato Democrático de Estudiantes. ¿Qué proponía el Decreto? Derrotado por el empuje del Movimiento Estudiantil, se vio obligado a reconocer la efectividad de todos los representantes intentando, simultáneamente, controlarlos mediante la creación de un sucedáneo pseudo-democrático: las Asociaciones Profesionales Estudiantiles (APE), dirigidas por un oscuro personaje de la Universidad de Granada llamado Ortega Escós, cuya adscripción ideológica era desconocida, pero que gozó de todas las bendiciones del Movimiento Nacional para publicitar una alternativa profesional y apolítica, tanto al SEU como a la concreción de los SDEU.

En realidad, tal como denuncia un documento conjunto de la Unión de Estudiantes Demócratas y la FUDE (Fernández Buey, 1977: 40-42), el Decreto presuponía la sumisión de los estudiantes a las autoridades académicas en todas sus actividades; la restricción de estas al más estricto profesionalismo y su adscripción a los principios del Movimiento Nacional. En definitiva, la negación de las libertades democráticas y de los medios de defensa imprescindibles para el funcionamiento de los SDEU, aún por constituir.

La agitación y rechazo de la propuesta gubernamental fue masiva. Las APE nacieron muertas. Y, en todo caso, sumaron al Movimiento Estudiantil a miles de estudiantes hasta entonces pasivos en su reivindicación de un sindicato independiente y autónomo, capaz de ejercer las libertades democráticas en el seno de la universidad, y de exigir los derechos de huelga y manifestación y unidos, muy especialmente, en el rechazo a un Decreto al que se calificaba de "nuevo y más sutil método de control que intenta montar un Régimen consciente de su debilidad y de que las viejas estructuras no pueden ya detener la creciente presión democrática de los estudiantes" (ibid..: 47).

El comienzo del curso 1965-1966 estuvo presidido por el rechazo a las APE en las universidades de Barcelona, Madrid y Sevilla. Diversos documentos $^{3}$ dan cuenta del alto grado de contestación estudiantil,

\footnotetext{
3 "Anteproyecto de programa democrático de la Universidad de Madrid", de 13-11-1965, y "Llamamiento de UDE-FUDE” y "Documento de 4.000 estudiantes y profesores de la Universidad de Barcelona”, dirigido al Rector García Valdecasas (Fernández Buey, 1977: 46-48; 51-52; y 58-61).
} 
máxime, cuando diversos catedráticos han sido expedientados por apoyar a los estudiantes y otros han dimitido en solidaridad. Algunos han protestado por escrito ante el Ministerio, encabezados por Laín Entralgo y Garrigues-Díaz Cañabate, y los más tibios se han adherido verbalmente a las protestas estudiantiles en el primer día de clase (Ruiz Giménez, Sampedro, Sáinz de Bujanda, etc). La situación ha cambiado. Por primera vez un exiguo pero significativo número de catedráticos apoyan, asumiendo diversos riesgos que en algún caso conllevó la separación de sus cátedras, las reivindicaciones estudiantiles. El proceso de acumulación de fuerzas está dando sus frutos y se ahonda, a mi juicio de forma significativa, el aprendizaje del movimiento estudiantil en la construcción de una ciudadanía democrática, ahora respaldada por lo mejor de la cúpula universitaria entonces existente, aunque se tratase de una escandalosa minoría entre los catedráticos de la universidad española.

Se acabó la soledad. Comienza una nueva etapa de la rebelión estudiantil que cristalizará otro mes de marzo, el de 1966, con la constitución del primer Sindicato Democrático de Estudiantes Universitarios en Barcelona, en un congreso celebrado en el convento de los frailes capuchinos de Sarriá (de nuevo, el apoyo de la Iglesia) con presencia de algunos profesores muy representativos de las diversas sensibilidades políticas presentes, desde las profesiones libertarias de Agustín García Calvo, a las comunistas del PSUC, representadas por Manuel Sacristán, culminando con las posturas catalanistas de un símbolo entre el profesorado de la Universidad de Barcelona: el profesor Rubió que, en catalán, se dirige a los estudiantes exigiendo la libertad universitaria y de estudio, mostrando su sorpresa y alegría por la madurez de los debates y de las decisiones adoptadas y expresando su esperanza de que un movimiento plural como suponía la creación del SDEU permita la transformación de la universidad. Termina, de forma emocionada, llamando a los estudiantes a tener confianza e ilusión en el camino emprendido, "como los viejos como yo la tenemos" y augurando el éxito por muchos que sean los obstáculos a vencer (Fernández Buey, 1977).

Los documentos aprobados dan cuenta de los principios, estatutos, órganos sindicales y finanzas del organismo, todos los cuales siguen las pautas de lo que hasta ahora hemos apuntado y que, con ligeras modificaciones adaptadas a las condiciones concretas de cada Distrito Universitario, serían aprobadas en todas las universidades españolas entre 1966 y 1967. Los principios de funcionamiento están regidos por una democracia asamblearia en la que asambleas de curso, Facultad y Distrito eran los órganos fundamentales de participación y, como tales, soberanos. Las 
tareas se distribuyen fundamentalmente en departamentos especializados de los que los más importantes eran el Departamento de Estudios Universitarios, el Departamento de Información y el Departamento de Actividades Culturales.

El primero, encargado de analizar y proponer alternativas en el plano académico-docente era el más cercano e importante para las decenas de miles de estudiantes que se estaban incorporando a la Universidad al calor del crecimiento económico del país y que acabarían masificando las aulas españolas, al menos, hasta la década de los ochenta. Un Departamento en el que, entre las fuerzas políticas concurrentes en el proceso, dominaron los estudiantes de adscripción católica progresista y, en menor medida, los adscritos a la pequeña corriente socialista.

El Departamento de Información cuyo objetivo era conectar las inquietudes sociopolíticas estudiantiles con el movimiento obrero, especialmente las ya constituidas Comisiones Obreras, con profesionales demócratas y con el incipiente movimiento de PNN's universitarios; fue copado por miembros del PCE y del PSUC que, sin duda, asumían los mayores riesgos, haciendo de carteles y panfletos su principal medio de expresión y convirtiéndose, por así decirlo, en una agencia de noticias independiente y alternativa a las establecidas por el Régimen y permitieron el ingreso del debate acerca de la necesaria democratización de la sociedad española en el centro de las preocupaciones y discusiones del movimiento estudiantil.

Por fín, el Departamento de Actividades Culturales que intentaba recoger la mejor tradición de la extensión universitaria española cuyas raíces se hundían en las Misiones Pedagógicas realizadas durante la Segunda República y que, mediante instrumentos muy variados (cineclubs, teatro independiente, recitales de poesía, conciertos, seminarios, etc) se reveló como un poderoso instrumento de agitación antifranquista y de participación activa o pasiva de miles de estudiantes que veían más o menos colmadas sus aspiraciones y anhelos de unas actividades culturales no mediatizadas directamente por la Dictadura y que sirvió también para despertar en unos y afianzar en otros la necesidad de unas nuevas pautas culturales y de extensión universitaria claramente democráticas, así como para que otros muchos pudiesen constatar atónitos que un recital, concierto o representación teatral era considerada por el Régimen como una actividad subversiva, calificación a la que muchos se opusieron y les llevó, de nuevo por otros caminos, a aspirar, a aprender y practicar nuevas formas culturales que, simultáneamente, eran prácticas de aprendizaje democrático. 
Como no podía ser de otro modo, pese a la relativa autonomía y libertad de las autoridades de los SDEU en el seno de las universidades, en el sentido de que lograron convertirse en los interlocutores válidos de la mayor parte de las autoridades académicas (Cátedras, Decanatos, y, en menor medida, Rectorados) en la vida cotidiana de las universidades, la represión no cesó.

Desde 1967 la presencia de las Fuerzas de Orden Público en las Universidades de Madrid y Barcelona fue cotidiana; la infiltración de miembros de la brigada político-social en las aulas era algo sabido por la mayoría de los estudiantes, así como la red de chivatos y delatores existentes en los cursos, muchas veces denunciados públicamente por los delegados de curso y los responsables de los SDEU; los expedientes y sanciones académicas a los dirigentes estudiantiles, su detención y puesta a disposición del Tribunal de Orden Público, las condenas a prisión o los destierros, estuvieron a la orden del día. Incluso la declaración por el Gobierno de Estado de Excepción en todo el territorio nacional, decretado en enero de 1969, tenía como principales objetivos desmantelar las estructuras de CCOO y de los SDEU.

El precio pagado fue alto: buena parte de los dirigentes estudiantiles, sobre todo los afiliados al PCE, dieron con sus huesos en las cárceles, fueron torturados por la policía en las comisarías, expedientados por las autoridades académicas y condenados, pues a perder el curso o les fueron denegadas las prórrogas para incorporarse al Servicio Militar en el que sistemáticamente fueron destinados a batallones de castigo o a las posesiones coloniales de Ceuta, Melilla o el Sáhara.

Lo que resultaba incomprensible para la Dictadura es que, pese a todo, nuevos dirigentes estudiantiles se incorporaban a la lucha, nuevas generaciones de jóvenes reclamaban democracia y libertad, surgían en las universidades un movimiento más peligroso por más estable, el de los jóvenes profesores no numerarios en cuyas espaldas recaía la mayor parte de la docencia universitaria, con unos salarios miserables, una absoluta precariedad laboral y una dependencia casi feudal de los catedráticos que decidían libremente sobre la procedencia o no de la renovación de contratos. Movimiento nuevo que se nutría de la cada vez mayor masificación en la universidad y que, en su mayoría, provenía de la organización sindical estudiantil, aunque fuese como afiliado de base, en cuyo clima habían realizado su primer aprendizaje de ciudadanía democrática y que sentían, como el alumnado, la necesidad de una reforma a fondo de la Universidad Española que en 1968 - también bajo la influencia y las expectativas despertadas por la rebelión estudiantil en los campus uni- 
versitarios europeos y norteamericanos - consideraban que sólo era posible si en España se instauraba la Democracia.

No debe extrañarnos pues que, a partir de 1968 y hasta el fin de la Dictadura (y aún durante la transición a la Democracia) el movimiento estudiantil se radicalizase y, al calor de las luchas y de las propias contradicciones internas de los partidos políticos de la oposición, buena parte de la dirección de las organizaciones estudiantiles, incluidas las primeras contestaciones a la estructura de los SDEU que comienzan a ser tachadas de "burocráticas", se desplazara a manos de militantes de los partidos de la Izquierda Revolucionaria o que también se alzasen voces disidentes en el seno de las organizaciones universitarias del PCE y del PSUC.

\section{El radicalismo estudiantil (1969-1975)}

Como señala el profesor Fernández Buey en la "Nota Introductoria" a la edición de documentos estudiantiles tantas veces citada, uno de los mayores handicaps del movimiento estudiantil es la escasa permanencia temporal de los estudiantes en las aulas universitarias. El rápido relevo del alumnado (aproximadamente, cinco años) obstaculiza no sólo la relativa estabilidad de los dirigentes, sino también la articulación de objetivos, métodos de lucha, análisis, etc. que es lo que dota de continuidad y de coherencia interna a cualquier movimiento social. En el movimiento estudiantil es muy característico "el abandono fulgurante de formas de organización que un día resultaron productivas, su sustitución por otras nuevas aún inexploradas y el retorno, en parte acrítico, a planteamientos pretéritos al primer síntoma de empobrecimiento de los recién introducidos" (Fernández Buey, 1977: 1).

$\mathrm{Y}$ aunque este rasgo tiene una faceta positiva: la radical oposición a la esclerosis y al burocratismo en el seno del movimiento, su tendencia constante a la renovación y a la regeneración, no es menos cierto que la casi total dispersión de los estudiantes egresados de la universidad constituye un factor de inconsistencia.

En el caso español, las particularidades del desarrollo del movimiento estudiantil en un sistema político dictatorial permitieron que, a lo largo del tiempo, existiesen un par de rasgos permanentes: la autoconsideración de formar parte, junto a otros movimientos sociales de las filas de una oposición cuyo objetivo común era la transformación de España en una sociedad de carácter genéricamente democrático ${ }^{4}$ y la defensa de la

\footnotetext{
${ }^{4}$ Digo "genéricamente democrático" porque el contenido que se le daba a este concepto variaba mucho dependiendo de la adscripción política de los estudiantes, según el grado de militancia en el movimiento e, incluso, de la región española de que se tratase. Por ejemplo estaba teñida de un fuerte contenido nacionalista en Cataluña y en el País Vasco.
} 
propia especificidad derivada de la reivindicación de reforma y autonomía de la universidad.

Por otro lado, las circunstancias internas de los partidos políticos que constituían la vanguardia de la oposición española también estaban cambiando. El PCE sufrió en la segunda mitad de los años sesenta diversas escisiones siempre con pretensiones más izquierdistas y revolucionarias, se forman nuevos partidos influidos por el maoísmo o el trotskismo con escasos pero muy activos militantes que se implantan con mayor facilidad en la universidad que en el mundo obrero; existe también una deriva de ciertos movimientos católicos de base hacia posiciones revolucionarias, casi siempre adoptando el marxismo-leninismo como seña de identidad. Grupos todos que tienen en común su posicionamiento frente a un PCE al que tachan de reformista; su dogmatismo y su escaso anclaje en un análisis objetivo de la realidad social española del momento.

Pese todos estos problemas, en el período que nos ocupa, los grupos de izquierda revolucionaria crecen y, a fuerza de optimismo, consiguen abrirse un importante espacio en la dirección del movimiento universitario: Bandera Roja, Partido del Trabajo de España (PTE), Organización Revolucionaria de Trabajadores (ORT), Movimiento Comunista (MC) o Liga Comunista Revolucionaria (LCR) son los núcleos principales que se convierten en parte de la vanguardia estudiantil pretendiendo siempre ir un paso más allá de las propuestas del PCE, tanto en el plano político como en el organizativo.

Uno de los principales caballos de batalla fue el de las formas de organización que cuestionaba la misma existencia de los SDEU. Así, en la revista UER (Unión de Estudiantes Revolucionarios) publicada por un grupo marxista-leninista en la Universidad de Barcelona se critica ferozmente la estructura sindical tachándola de "parlamentarismo burocrático" que solo fomentaba la pasividad del conjunto de los estudiantes. Se le criticaba de llevar a cabo una actividad puramente "representativa y democrática", no revolucionaria. De parcializar la realidad política para llegar a más gente, a costa de desligarse de la lucha contra un sistema "en esencia represivo" al que el movimiento estudiantil debe denunciar y enfrentarse de forma radical. Se propugnan nuevas formas organizativas basadas en las Asambleas entendidas como instrumentos temporales para asegurar la discusión y el control de tareas concretas y unas Comisiones de carácter operativo y unos Comités de Acción que permitan abordar nuevas formas de lucha: ocupación de cátedras y ocupación de sus titulares, lucha directa contra la policía que ocupaba la universidad, etc. Todo ello en la perspectiva de una universidad controlada por los estudiantes 
y de apoyo a la lucha obrera "contra el Estado Burgués y por la construcción del Socialismo” (Fernández Buey, 1977: 100-104 y 112-116).

Ahora prima la idea de un movimiento estudiantil de carácter anticapitalista y revolucionario que no obvia el recurso a la violencia y que cita profusamente a Mao o al Che Guevara. Incluso Universitat, órgano del Comité Universitario del PSUC se distancia en 1969 del SDEU y, aún reconociendo el papel que ha jugado, se muestra partidario de los "Comités de Acción”, eso sí, dotándolos de una dirección política que, naturalmente, solo ellos pueden realizar (Fernández Buey, 1977: 129-135).

En 1971, Tribuna Roja, órgano del sector universitario de Bandera Roja publica unas "tesis sobre el movimiento estudiantil" realizadas con mayor esmero y finura de análisis político que advierte de los cambios producidos en la extracción social de los estudiantes que ahora proceden de las capas medias urbanas y cuya posición política es inestable, sensible al tecnocratismo y al nacionalismo pequeño burgués, pero también sensible a una opción comunista que defienda los movimientos populares.

Desde el punto de vista organizativo, también entierran la experiencia sindical y propone la creación de Comités de Curso como células básicas del movimiento cuyo objetivo es politizar al alumnado en la lucha antifranquista y contra el capital monopolista, para ligarlo al conjunto del movimiento popular revolucionario. Sus propuestas estrictamente universitarias son mucho más pobres y se acercan mucho a las del PSUC que tanto combaten. En este sentido, proponen una plataforma reivindicativa que aspira a una universidad con "una cultura amplia", abierta y capaz de permitir el ingreso de las capas sociales más humildes mediante una política de ampliación de becas y de lucha contra la selectividad como requisito de ingreso; una universidad que garantice el ejercicio de las libertades democráticas (especialmente las de expresión, reunión y asociación) y que aumente el nivel de formación del alumnado con un profesorado contratado no vitalicio; exigen la reducción del número de alumnos por grupo, la creación de bibliotecas y laboratorios especializados que posibiliten el inicio en la investigación y la intervención del alumnado en el control de los exámenes (Fernández Buey, 1977: 143-162).

Es decir, mucho discurso presuntamente radical y plataformas que puedan ser asumidas por la mayoría de los estudiantes. Probablemente esta sea la gran contradicción de la izquierda revolucionaria en la universidad. Sus propuestas generales, anticapitalistas, antiburocráticas y prosocialistas sólo son entendidas por un pequeño sector del alumnado más politizado: lo que, en la jerga de la época se denominaba "la izquierda de las masas", mientras que el conjunto del alumnado estaba muy lejano de 
tales inquietudes. ¿Supone esto que la tarea de radicalización fue vana?. Probablemente, no. Sirvió, en primer lugar, para profundizar en el debate sobre el carácter y función de la universidad en la sociedad capitalista, para acercar, si quiera conceptualmente, a los estudiantes unas inquietudes y unos problemas que formaban parte del acervo común del movimiento estudiantil europeo; par concienciar a un sector minoritario, pero significativo, de alumnos y para introducir en el movimiento conceptos antiburocráticos, socialistas, feministas y antiautoritarios que pretendían ser los valores principales en una profundización de la democracia en España que condujese al socialismo. Propuestas utópicas, sin duda, pero no quiméricas en la medida en que pusieron en cuestión las exigencias democráticas mínimas que, con más realismo, propugnaban los partidos mayoritarios como si de conquistas máximas se tratase.

Desde una perspectiva más inmediata al momento histórico del que tratamos, las formas de lucha propugnadas por la izquierda radical solo condujeron a las páginas de sucesos de la prensa y a la creación en amplios sectores de la opinión pública, pacata y constreñida por la censura, de la idea de que el movimiento estudiantil era un nido de revoltosos inconscientes o, lo que era peor, de enemigos de la convivencia pacífica. Incluso entre los sectores mayoritarios del propio movimiento que aceptaban sin problemas las nuevas fórmulas organizativas, no se compartían muchas de las formas propuestas, especialmente aquellas que incluían la violencia explícita.

Por otro lado, es preciso poner de relieve las importantes diferencias existentes entre los distritos universitarios de Madrid y Barcelona, que contaban con mayor número de estudiantes y de facultades, que estaban mucho más politizados y cuyo eco mediático era mayor, y el resto de las universidades ("de provincias" se decía entonces) en las que la influencia de los diversos partidos políticos era infinitamente menor, aunque la organización del movimiento estudiantil estuviese muy mediatizada por ellos.

Las propuestas organizativas, de formas de lucha y de objetivos fueron mucho más cercanas y, en esa medida, posibles de asumir por el conjunto del alumnado sin que esto suponga una "rebaja" en el contenido político del movimiento estudiantil. Luchas como las llevadas a cabo contra el Consejo de Guerra de Burgos en diciembre de 1970 en el que fueron condenados a muerte activistas de ETA o la llevada a cabo contra la Ley General de Educación del ministro opusdeísta Villar Palasí en 1971 movilizaron a decenas de miles de universitarios en todo el territorio nacional y condujeron al cierre de las facultades más combativas por parte 
de las autoridades académicas que condenaron a la condición de alumnos libres, con solo derecho a examen final, a miles de estudiantes que, pese a todas las amenazas, decidieron continuar la lucha concretada en huelgas y manifestaciones.

Obviamente, eso solo podía ocurrir si el apoyo al movimiento estudiantil y a sus dirigentes era mayoritario en las universidades; si los estudiantes tenían la posibilidad de tomar decisiones, de debatirlas, de cuestionar las diversas propuestas, de reconocer y apoyar a sus representantes como personas en las que se podía confiar, etc. Cuestiones todas ellas que, a mi juicio, constituyen elementos fundamentales del aprendizaje y de la práctica de la democracia dentro de la universidad que - como lluvia fina - fue empapando a diversas generaciones estudiantiles españolas ayudándolas a instalarse en una cultura de la ciudadanía que exigía derechos y asumía deberes y cuya contribución al proceso de transición a la democracia en España resultó decisiva. Como decisivo fue que muchos de los protagonistas de primera y segunda fila de ese proceso de transición se hubiesen formado política y culturalmente en las filas del movimiento estudiantil antifranquista. Pero esta es otra cuestión que quizás mereciese otra ponencia en otro congreso.

\section{Referencias bibliográficas}

Claret Miranda, J. (2005), La repressió franquista a'universitat espayola. Barcelona: Universitat Pompeu Fabra.

Fernández Buey, Francisco (1977), "Documentos del Movimiento Universitario durante el franquismo”, Materiales, Extraordinario número 1.

Poulantzas, Nikos (1976), La crisis de la dictadura. Madrid: Siglo XXI. 